\title{
A randomized controlled double blind study comparing the efficacy of epidural ropivacaine and bupivacaine with fentanyl for labor analgesia
}

\author{
Rakhee .S , Shalini Miriam Ipe ${ }^{2, *}$, Saramma P. Abraham ${ }^{3}$, Shaloo Ipe ${ }^{4}$, Sam Philip \\ ${ }^{\mathbf{1}}$ Associate Professor, ${ }^{2}$ Assistant Professor, ${ }^{3,4,5}$ Professor, Dept. of Anaesthesiology, MOSC Medical College, Kolenchery, Kerala, \\ India
}

*Corresponding Author: Shalini Miriam Ipe

Email: shalinimiriamipe@gmail.com

\begin{abstract}
Introduction and Aim: Ropivacaine and bupivacaine have been found to provide adequate labor analgesia when given epidurally. The aim of this randomized double blind study was to compare the onset of sensory block in epidural ropivacaine and bupivacaine with Fentanyl for labor analgesia and to assess the maternal and fetal outcome.

Materials and Methods: In this prospective double blind study, 60 ASA II parturients with singleton vertex presentation were randomly allocated to two groups of 30 each. Group R received $5 \mathrm{ml} 0.2 \%$ ropivacaine with 50mcg Fentanyl as bolus, followed by continuous infusion of ropivacaine $0.1 \%$ with Fentanyl $1 \mathrm{mcg} / \mathrm{ml}$ at $6 \mathrm{ml} / \mathrm{hr}$. Group B received $5 \mathrm{ml} 0.125 \%$ bupivacaine with $50 \mathrm{mcg}$ Fentanyl as bolus, followed by continuous infusion of bupivacaine $0.0625 \%$ with Fentanyl $1 \mathrm{mcg} / \mathrm{ml}$ at $6 \mathrm{ml} / \mathrm{hr}$. Onset and regression of sensory level, degree of motor block, hemodynamic effects, mode of delivery, neonatal outcome and patient satisfaction were compared. The statistical analysis was done using the Mean, Standard Deviation and the student ' $t$ ' test.

Results: There was a significantly faster onset of sensory block with ropivacaine $(5.67 \pm 0.99 \mathrm{~min})$ compared to bupivacaine $(6.67 \pm 1.39 \mathrm{~min})(\mathrm{p}<0.05)$. There were no significant differences between the groups regarding the duration, quality of analgesia, degree of motor block, hemodynamic parameters, mode of delivery, neonatal safety and patient acceptability.

Conclusion: Ropivacaine provides effective analgesia with faster onset of sensory block in comparison to bupivacaine and is safe for mother and fetus.
\end{abstract}

Keywords: Labor analgesia, Epidural, Bupivacaine, Ropivacaine, Fentanyl.

\section{Introduction}

"The delivery of the infant into the arms of a conscious and pain - free mother is one of the most exciting and rewarding moments in medicine"- Moir. ${ }^{1}$ Labor analgesia is very effective in decreasing the maternal and perinatal morbidity due to pain activated sympathetic stimulation. Of the various methods of labor analgesia, local anesthetics and opioids via epidural gives the most effective analgesia. Local anesthetics used must have rapid onset, long duration of action, no motor blockade and should be safe for both mother and baby. Bupivacaine was used earlier at a concentration of $0.125 \%-0.0625 \%$ with Fentanyl. Ropivacaine is thought to be better compared to bupivacaine producing lesser motor block, thus preserving the tone of pelvic floor muscles and retaining the sensation of baby's head facilitating the ability to push. ${ }^{2}$ The addition of opioid Fentanyl with its lipid solubility and lower incidence of side effects allows the use of lesser concentration of local anesthetics again reducing the degree of motor block. This study was designed with the objective of comparing the onset of sensory block, analgesic efficacy, motor blockade and maternal and neonatal outcome of ropivacaine in contrast to bupivacaine.

\section{Materials and Methods}

After obtaining written informed consent and Institutional Ethical Committee approval, this prospective randomized double blind study was conducted in a tertiary care teaching hospital in Kerala over a period of 18 months. Parturients in labor who requested epidural labor analgesia and without any contraindication to epidural were enrolled in this study. Parturients with bleeding disorders, decreased platelet count, infection at the site of injection and spinal column anomalies were excluded.

A sample size of minimum of 28 subjects per group was required to obtain a statistical significance assuming an $\alpha$ error of 0.05 and power of 0.9 . Hence 60 parturients of the age group 20-40yrs and physical status of ASA II chosen for the study were randomly divided into 2 groups of 30 each. Randomization was done using sealed envelope technique. The patient, obstetrician, anaesthesiologist and the neonatologist were blinded to the study group. Double blindedness was ensured by involving different anesthesiologists to prepare the study drug, administer epidural and record the observations.

Age, height, weight, baseline blood pressure and pulse rate were recorded to see that the groups were comparable. Systemic examination, assessment of airway and spine were done. The stage of labor was determined by the duration and frequency of uterine contractions and the degree of cervical dilatation by the obstetrician. Baseline Foetal heart rate (FHR) was recorded. Routine investigations like hemoglobin, total and differential count and urine examination were done 
for all parturients. Parturients were explained of the procedure in advance. Visual Analogue Scale used for evaluating pain was also explained to the parturients. Continuous monitoring of pulse rate, non invasive blood pressure, electrocardiogram, oxygen saturation and respiratory rate was done using monitors with trend facilities. Oxygen was administered to all parturients via a simple face mask at $6 \mathrm{~L} /$ minute. Equipment for resuscitation, vasopressors, emergency drugs, oxygen source and suction apparatus were kept ready. All parturients were preloaded with $500 \mathrm{ml}$ of ringer lactate. Injection ondansetron $4 \mathrm{mg}$ intravenously was given to all parturients. In the lateral decubitus position, under aseptic precautions epidural space was identified at L3 - L4 space with an 18G Tuohy needle using loss of resistance to air technique. The epidural catheter was advanced $2 \mathrm{cms}$ into the epidural space. $3 \mathrm{ml}$ of $1.5 \%$ lignocaine with $15 \mu \mathrm{g}$ adrenaline was given as test dose to rule out intravascular or intrathecal placement. Five minutes after the test dose, the bolus dose of the drug was given making the patient supine with a wedge under the right buttock. Continuous infusion of the drug was started 30 minutes after the bolus dose. The drug dosing was as follows.

Table 1: Study groups

\begin{tabular}{|c|c|c|}
\hline Groups & Bolus & Continuous epidural infusion \\
\hline Group R & $\begin{array}{l}5 \mathrm{ml} \text { of } 0.2 \% \text { Ropivacaine with } 50 \mu \mathrm{g} \text { Fentanyl } \\
\text { (Total- } 6 \mathrm{ml} \text { ) }\end{array}$ & $\begin{array}{c}\text { Ropivacaine } 0.1 \% \text { with Fentanyl } 1 \mu \mathrm{g} / \mathrm{ml} \text { at } 6 \\
\mathrm{ml} / \mathrm{hr} \text {. }\end{array}$ \\
\hline Group B & $\begin{array}{l}5 \mathrm{ml} \text { of } 0.125 \% \text { bupivacaine with } 50 \mu \mathrm{g} \text { Fentanyl } \\
\text { (Total-6ml) }\end{array}$ & $\begin{array}{c}\text { bupivacaine } 0.0625 \% \text { with Fentanyl } 1 \mu \mathrm{g} / \mathrm{ml} \\
\text { at } 6 \mathrm{ml} / \mathrm{hr} \text {. }\end{array}$ \\
\hline
\end{tabular}

A test dose of $3 \mathrm{ml}$ lignocaine with adrenaline was given before administering the bolus, hence a bolus dose of $6 \mathrm{ml}$ was effective in producing labor analgesia with a VAPS score of $<3$.

$0.2 \%$ ropivacaine will become equipotent to $0.125 \%$ bupivacaine which is used as bolus and $0.1 \%$ ropivacaine is equipotent to $0.0625 \%$ bupivacaine which is used as infusion, as the potency ratio is 0.6. Polley et $\mathrm{al}^{4}$ concluded that ropivacaine was significantly less potent than bupivacaine, with potency ratio of 0.6 .

All parturients were monitored in supine position with a left uterine displacement of 15 degree with a wedge under right buttock to prevent aortocaval compression. Epidural infusion was maintained throughout labor. Once pain relief was achieved by epidural, Oxytocin was administered in titrated doses to enhance labor. In the event of break through pain, $5 \mathrm{ml}$ of the infusion drug $(0.1 \%$ ropivacaine or $0.0625 \%$ bupivacaine, with $1 \mu \mathrm{g} / \mathrm{ml}$ fentanyl) was given as a bolus dose. At second stage of labor, a bolus of $5 \mathrm{ml}$ of the infusion drug was given maintaining sitting up position for 5 minutes to achieve perineal analgesia during delivery of the fetus. However, if maternal effort was judged to be inadequate by the attending obstetrician, the anaesthesiologist was called to assess the parturient to reduce or stop the epidural infusion as considered appropriate. Adequacy of analgesia was assessed by the patient's subjective feeling of relief of pain and the visual analogue pain scale. Visual Analogue Pain Scale (VAPS) chosen was a $100 \mathrm{~mm}$ linear scale on which 0 represented no pain and 100, the worst possible pain. Evaluation was carried out before giving epidural and at 5minutes interval for first 30minutes of bolus injection and then every hour till birth of the baby. An additional VAPS score was obtained at the time of delivery. Analgesia was considered adequate if pain score was $\leq 3$. Onset of analgesia was defined as the time of first bolus dose to the time of achieving VAPS $\leq 3$. The sensory level was assessed by pin prick method using a 26G hypodermic needle. The total duration of analgesia was calculated from the onset of pain relief to the end of analgesia. Regression of sensory level was assessed after delivery by pin prick method. Time taken for regression of two dermatomal levels from the initial dermatomal level was considered as the regression time. The degree of motor block was graded according to Modified Bromage scale. (1 - complete motor blockade, Inability to move feet or legs, 2 - patient is able to move the feet, 3 - able to move knees, 4 - detectable weakness of hip flexion, able to raise legs but unable to keep them raised, 5 - no detectable weakness while supine, 6 - able to perform knee bend while standing. $)^{5}$ Score 6 was not assessed because it was difficult to make the parturients stand up. Motor block was defined as a Modified Bromage scale of $\leq 4$. The degree of motor block, mode of delivery and the APGAR score of neonate at 1 and 5 minutes were noted. The neonatal assessment was done by the neonatologist. Patients were also observed for complications like respiratory depression, nausea, vomiting, pruritus, urinary retention and hemodynamic effects. Hypotension defined as a $20 \%$ fall from the basal systolic blood pressure or below $90 \mathrm{~mm}$ of $\mathrm{Hg}$ was managed by giving Ephedrine 3-6 mg intravenous boluses and rapid infusion of Ringer Lactate. Bradycardia defined as a heart rate below 50/minute was treated with Atropine $0.6 \mathrm{mg}$ IV. Respiratory depression was taken as respiratory rate less than 10 per minute and desaturation as $\mathrm{SPO}_{2}$ less than $94 \%$. After delivery, patient's satisfaction was assessed by a Numerical Rating score based on a four point scale. (1=excellent, 2=good, 3=fair, 4=poor) ${ }^{6}$ Labor was managed according to our Obstetric Department protocol and mode of delivery was noted. If the decision for Caesarean delivery was made, anaesthesia 
was achieved by a bolus of $2 \%$ lignocaine with adrenaline $15 \mathrm{ml}$ and titrating with $2 \mathrm{ml}$ increments if found necessary. Parturients were shifted out to the ward from the labor room after passing urine.

\section{Statistical Analysis}

Statistical analysis was done using IBM SPSS - 22 version software. Continuous variables were presented as Mean \pm Standard deviation. A p-value of $<0.05$ was considered statistically significant and a P-value of $<$ 0.01 as highly significant.

\section{Results}

A total of 60 ASA II parturients were assigned to either ropivacaine group $(\mathrm{R})$ or bupivacaine group $(\mathrm{B})$. Comparison of groups were done under different categories like onset and regression of sensory block, degree of motor block, hemodynamic effects, mode of delivery, maternal and neonatal outcome, patient satisfaction and complications.

Both groups were similar in distribution of demographic parameters like age, height and weight as evidenced by statistical analysis.

Table 2: Demographic data

\begin{tabular}{|l|c|c|c|}
\hline & Group A & Group B & P value \\
\hline Age $(\mathrm{yr})$ & $25.06 \pm 2.65$ & $24.30 \pm 1.62$ & 0.1802 \\
\hline Height $(\mathrm{cm})$ & $158.61 \pm 6.27$ & $157.85 \pm 4.49$ & 0.5892 \\
\hline Weight $(\mathrm{kg})$ & $66.57 \pm 8.90$ & $68.19 \pm 9.79$ & 0.5029 \\
\hline
\end{tabular}

Onset of sensory block: Onset of sensory block was significantly faster in ropivacaine group $(5.67 \pm 0.99$ $\min )$ as compared to bupivacaine group $(6.67 \pm 1.39$ $\min )(P=0.0013)$ which was highly significant.

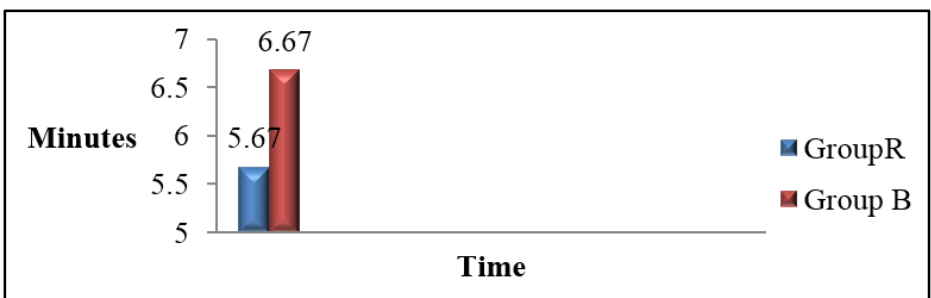

Fig. 1: Onset of sensory block

Ropivacaine group achieved VAPS score $\leq 3$ earlier than bupivacaine group though not statistically significant $(\mathrm{P}=0.23)$.

Table 3: VAPS Score and regression of sensory level

\begin{tabular}{|l|c|c|c|}
\hline & Group R & Group B & P value \\
\hline VAPS before epidural & $7.53 \pm 0.82$ & $7.17 \pm 0.85$ & 0.09 \\
\hline VAPS after epidural & $0.43 \pm 0.57$ & $0.27 \pm 0.45$ & 0.23 \\
\hline Regression of sensory level & $164.17 \pm 68.26$ & $181.17 \pm 48.09$ & 0.26 \\
\hline
\end{tabular}

Motor block: None of our patients in either group had motor power of less than grade 5 .

Hemodynamic and Respiratory Parameters: Hemodynamic and respiratory parameters were comparable and acceptable among both the groups. None of the patients required ephedrine or atropine injection.

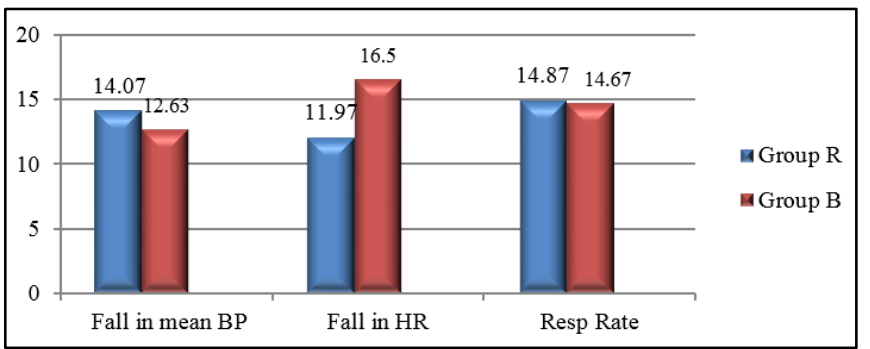

Fig. 2: Hemodynamic and respiratory parameters

Foetal heart rate, baby weight and APGAR score were comparable in both groups. APGAR at 1' and 5', were normal. APGAR score at $1 \mathrm{mt}$ was 7 or above and at $5 \mathrm{mts}$ was 10. None of the babies needed ICU admission. 
Mode of delivery: Mode of delivery (Normal, LSCS and Instrumental) was comparable in both the groups.

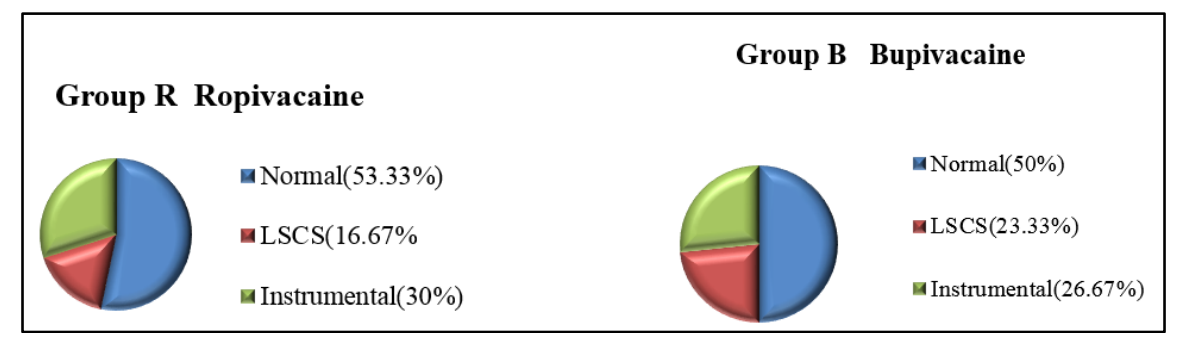

Fig. 3: Distribution according to mode of delivery

Top ups: $73.33 \%$ of Group B and $40 \%$ of Group R parturients required top up doses in addition to the continuous infusions and this difference was statistically significant with a $\mathrm{p}$ value of 0.0057 .

\section{\% Requiring Top Ups}

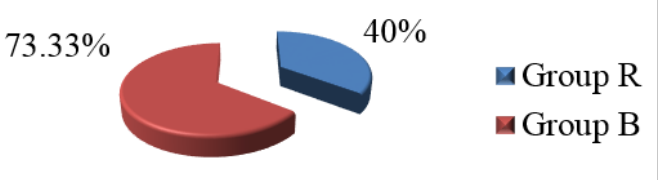

Quality of Analgesia: Quality of analgesia assessed using Numerical Rating Scale (NRS) revealed that both the groups had excellent analgesia following epidural injections $(\mathrm{p}=0.30)$.

Complications: Number of parturients having a subjective feeling of numbness was significantly more in bupivacaine group in comparison to ropivacaine group $(p=0.0302)$. Nausea and vomiting were not observed in any of the parturients. Incidence of pruritus and urinary retention, though very few were similar in both the groups. None of our patients had accidental dural puncture.

Fig. 4: Requirement of top ups

\section{Fig. 5: Complications}

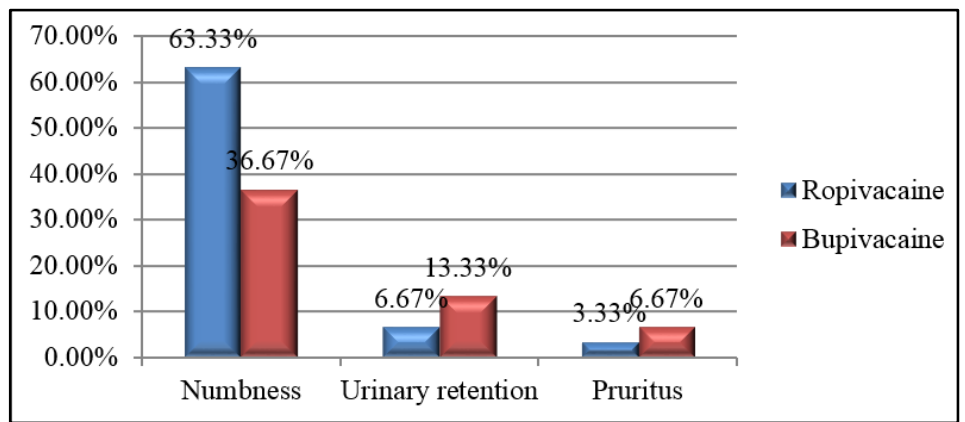

\section{Discussion}

In our institution, around $20 \%$ of the parturients in labor demand epidural analgesia for pain relief during delivery. Lower concentrations of local anesthetics like ropivacaine and bupivacaine along with Fentanyl has been used as a bolus followed by continuous infusion.

Present study compared the onset of sensory block between ropivacaine and bupivacaine. There was a significantly faster onset of sensory block with ropivacaine compared to bupivacaine (5.67 min versus $6.67 \mathrm{~min}, \mathrm{p}=0.0013$ ). Shokry et al. ${ }^{7}$ compared $0.125 \%$ bupivacaine and $0.2 \%$ ropivacaine, each with Fentanyl $100 \mu \mathrm{g}$ and found a faster onset of sensory block with ropivacaine like in our study. Contrary to our findings, Bawdane et al's $\mathrm{s}^{8}$ double blind comparison of $0.1 \%$ ropivacaine to $0.1 \%$ bupivacaine each with Fentanyl for labor analgesia showed that both the drugs were similar in respect to the onset of sensory blockade. In our study, two dermatomal sensory level regression time was similar in both the groups. Kanai et $\mathrm{al}^{9}$ who compared the regression of sensory level in continuous epidural infusion of $0.2 \%$ ropivacaine and $0.125 \%$ bupivacaine (similar to the concentration we used) postoperative patients found that regression of sensory level was significantly prolonged in patients treated with ropivacaine.

Highly effective analgesia in terms of duration and quality was achieved in both the study groups. Girard et al. ${ }^{10}$ and Owen et $\mathrm{al}^{6}$ in their study comparing $0.125 \%$ bupivacaine and $0.125 \%$ ropivacaine with Fentanyl found that both were equally effective for labor analgesia.

Motor block was not observed in both the groups studied. This was contrary to our expectation of finding motor block in the bupivacaine group as it does not 
possess the advantage of preferential sensory block like ropivacaine. This could be due to the fact that the lower concentrations $(0.1 \%$ ropivacaine and $0.0625 \%$ bupivacaine as infusion) that we used does not produce any motor block. This was in accordance with the studies by Stienstra et al, ${ }^{11}$ Owen et al, ${ }^{6}$ Bawdane et $\mathrm{al}^{8}$ and Girard et al. ${ }^{10}$ Meister et al. ${ }^{12}$ using $0.125 \%$ ropivacaine and $0.125 \%$ bupivacaine with $2 \mu \mathrm{g} / \mathrm{ml}$ of Fentanyl in PCEA for labor analgesia showed that ropivacaine had significantly less motor block than bupivacaine. The reason for higher degree of motor block in bupivacaine group may be due to the higher concentration of bupivacaine they used $(0.125 \%$ versus $0.0625 \%)$. A meta analysis by Halpern and Walsh ${ }^{13}$ of 23 randomized controlled trials using varying concentrations of bupivacaine and ropivacaine also showed increased incidence of motor block with bupivacaine.

Mode of delivery was comparable between the groups. We expected more spontaneous vaginal deliveries in the ropivacaine group in view of its proposed lesser motor blockade. The intact motor power of the pelvic floor helps rotation of the presenting part and also augments the expulsive forces helping spontaneous vaginal delivery. In our study, there was no motor block in both the groups which might explain similar mode of delivery. Bawdane et $\mathrm{al}^{8}$ compared $0.1 \%$ ropivacaine and $0.1 \%$ bupivacaine with Fentanyl and found no difference in the mode of delivery. In contrary, Writer et al. ${ }^{14}$ and Mccrae et al ${ }^{15}$ using higher concentration of bupivacaine and ropivacaine observed a greater frequency of spontaneous vaginal delivery and lesser motor blockade with ropivacaine. Campbell and his colleagues ${ }^{11}$ in their study using $0.08 \%$ concentration of ropivacaine and bupivacaine with Fentanyl $2 \mu \mathrm{g} / \mathrm{ml}$ showed less motor block and more spontaneous vaginal delivery in ropivacaine group.

In our study, bupivacaine group needed significantly more number of top ups than ropivacaine group $(p=0.0057)$. Similar results were obtained by Dresner et $\mathrm{al}^{16}$ who compared $0.2 \%$ ropivacaine with $0.1 \%$ bupivacaine and Fentanyl $2 \mu \mathrm{g} / \mathrm{ml}$. Top ups were given as $5 \mathrm{ml}$ boluses of the infusion drug $(0.1 \%$ ropivacaine with $1 \mu \mathrm{g} / \mathrm{ml}$ fentanyl or $0.0625 \%$ bupivacaine with $1 \mu \mathrm{g} / \mathrm{ml}$ fentanyl) for break through pain.

In our study, significant numbness was observed in patients receiving bupivacaine than ropivacaine. ( $p=$ 0.0302). Increased number of top ups in bupivacaine group may explain this. Hemodynamic, respiratory, neonatal parameters and patient acceptability were comparable in both our study groups. Fernandez Guisasola $^{17}$ and associates who compared $0.0625 \%$ bupivacaine and $0.1 \%$ ropivacaine with fentanyl $2 \mu \mathrm{g} / \mathrm{ml}$ also found similar characteristics in hemodynamic variables, neonatal outcome and patient satisfaction.

Nausea and vomiting were not seen in both groups, may be because of injection Ondansetron $4 \mathrm{mg}$ given intravenously $8^{\text {th }}$ hourly. Pruritus and urinary retention which occurred were comparable in both the groups. Pruritus found in a small number of patients may be attributed to the Fentanyl given epidurally. Bawdane et $\mathrm{al}^{8}$ and Paddalwar et $\mathrm{al}^{18}$ found similar incidence of nausea, vomiting, pruritus and urinary retention in his study groups of ropivacaine and bupivacaine. Unlike in our study, Campbell et $\mathrm{al}^{19}$ compared $0.08 \%$ ropivacaine and bupivacaine with Fentanyl and found ropivacaine better than bupivacaine in preserving the ability of the parturient to micturate and ambulate.

\section{Conclusion}

Ropivacaine $(0.2 \%$ with $50 \mu \mathrm{g}$ Fentanyl bolus followed by $0.1 \%$ with Fentanyl as continuous infusion) provides faster onset of sensory block compared to bupivacaine $(0.125 \%$ with $50 \mu \mathrm{g}$ Fentanyl bolus followed by infusion $0.0625 \%$ with Fentanyl), both providing effective analgesia and comparable obstetric outcome and was found to be safe for the mother and neonate.

The use of lignocaine with adrenaline as test dose may distort the results of the study. We could have avoided the test dose and instead boluses of low concentration of local anesthetic opioid combination could have been given as test dose.

\section{Conflicts of Interest: None.}

\section{References}

1. Moir DD. Extradural analgesia for caesarean section. Br J Anaesth. 1979;51(2):79-80.

2. Lacassie HJ, Columb MO, Lacassie HP, Lantadilla RA. The relative motor blocking potencies of epidural bupivacaine and ropivacaine in labor. Anesth Analg. 2002;95(1):204-248.

3. D'Angelo R, Gerancher JC, Eisenach JC, Raphael BL. Epidural Fentanyl Produces Labor Analgesia by a Spinal Mechanism. Anesthesiol J Am Soc Anesthesiol. 1998;88(6): 1519-1523.

4. Polley LS, Columb MO, Naughton NN, Wagner DS, van de Ven CJ. Relative analgesic potencies of ropivacaine and bupivacaine for epidural analgesia in labor: implications for therapeutic indexes. Anesthesiol. 1999;90(4):944-950.

5. Clément HJ, Caruso L, Lopez F, Broisin F, Blanc-Jouvan $\mathrm{M}$, Derré-Brunet E. Epidural analgesia with $0.15 \%$ ropivacaine plus sufentanil $0.5 \mu \mathrm{g} \mathrm{ml}-1$ versus $0.10 \%$ bupivacaine plus sufentanil $0.5 \mu \mathrm{g} \mathrm{ml}-1$ : a double-blind comparison during labour. Br J Anaesth. 2002;88(6):809813.

6. Owen MD, D'Angelo R, Gerancher JC, Thompson JM, Foss ML, Babb JD, et al. $0.125 \%$ ropivacaine is similar to $0.125 \%$ bupivacaine for labor analgesia using patientcontrolled epidural infusion. Anesth Analg. 1998;86(3):527-531.

7. Shokry M, Manaa EM, Shoukry RA, Shokeir MH, Elsedfy GO, Abd El-Aziz AE-S. Effects of intrapartum epidural analgesia at high altitudes: maternal, fetal, and neonatal outcomes. A randomized controlled trial of two formulations of analgesics. Acta Obstet Gynecol Scand. 2010;89(7):909-915. 
8. Bawdane K, Magar J, Tendolkar B. Double blind comparison of combination of $0.1 \%$ ropivacaine and fentanyl to combination of $0.1 \%$ bupivacaine and fentanyl for extradural analgesia in labour. J Anaesthesiol Clin Pharmacol. 2016;32(1):38.

9. Kanai A, Osawa S, Suzuki A, Ozawa A, Okamoto H, Hoka S. Regression of sensory and motor blockade, and analgesia during continuous epidural infusion of ropivacaine and fentanyl in comparison with other local anesthetics. Pain Med Malden Mass. 2007;8(7):546-553.

10. GIRARD T, KERN C, HÖSLI I, Heck A, SCHNEIDER MC. Ropivacaine versus Bupivacaine $0.125 \%$ with Fentanyl $1 \mu \mathrm{g} / \mathrm{ml}$ for Epidural Labour Analgesia : Is Daily Practice More Important Than Pharmaceutical Choice? 2006;5.

11. Stienstra R. Patient-controlled epidural analgesia or continuous infusion: advantages and disadvantages of different modes of delivering epidural analgesia for labour. Curr Opin Anaesthesiol. 2000;13(3):253-256.

12. Meister GC, D'Angelo R, Owen M, Nelson KE, Gaver R. A comparison of epidural analgesia with $0.125 \%$ ropivacaine with fentanyl versus $0.125 \%$ bupivacaine with fentanyl during labor. Anesth Analg. 2000;90(3):632-637.

13. Halpern $\mathrm{SH}$, Walsh V. Epidural ropivacaine versus bupivacaine for labor: a meta-analysis. Anesth Analg. 2003;96(5):1473-1479.

14. Writer WD, Stienstra R, Eddleston JM, Gatt SP, Griffin $\mathrm{R}$, Gutsche BB, et al. Neonatal outcome and mode of delivery after epidural analgesia for labour with ropivacaine and bupivacaine: a prospective metaanalysis. BJA Br J Anaesth. 1998;81(5):713-717.

15. Mccrae AF, Jozwiak H, Mcclure JH. Comparison of ropivacaine and bupivacaine in extradural analgesia for the relief of pain in labour. BJA Br J Anaesth. 1995;74(3):261-265.

16. Dresner M, Freeman J, Calow C, Quinn A, Bamber J. Ropivacaine $0.2 \%$ versus bupivacaine $0.1 \%$ with fentanyl: a double blind comparison for analgesia during labour. BJA Br J Anaesth. 2000;85(6):826-829.

17. Fernández-Guisasola J, Serrano ML, Cobo B, Muñoz L, Plaza A, Trigo C, et al. A comparison of $0.0625 \%$ bupivacaine with fentanyl and $0.1 \%$ ropivacaine with fentanyl for continuous epidural labor analgesia. Anesth Analg. 2001;92(5):1261-1265.

18. Paddalwar S, Nagrale M, Chandak A, Shrivastava D, Papalkar J. A randomized, double-blind, controlled study comparing Bupivacaine $0.125 \%$ and Ropivacaine $0.125 \%$, both with Fentanyl $2 \mu \mathrm{g} / \mathrm{ml}$, for labor epidural analgesia. Indian J Pain. 20131;27(3):147.

19. Campbell DC, Zwack RM, Crone LA, Yip RW. Ambulatory labor epidural analgesia: bupivacaine versus ropivacaine. Anesth Analg. 2000;90(6):1384-1389.

How to cite this article: Rakhee .S, Ipe S.M, Abraham S. P, Ipe S, Philip S. A randomized controlled double blind study comparing the efficacy of epidural ropivacaine and bupivacaine with fentanyl for labor analgesia. Indian $\mathrm{J}$ Clin Anaesth. 2018;5(4):614-619. 